\title{
Nutrient composition and in vitro degradability of some tropical shrubs from Pakistan \\ M R Virk ${ }^{1,2}$, A S Chaudhry ${ }^{1}$ \\ ${ }^{1}$ Newcastle University, Newcastle upon Tyne, United Kingdom, ${ }^{2}$ University of Agriculture, Faisalabad, Pakistan \\ Email: a.s.chaudhry@ncl.ac.uk
}

Introduction The range livestock production in Pakistan mostly depends on post harvest grazing or grazing on marginal or salty or waterlogged lands that are not suitable for traditional crops. Due to regional variations in the quality of grazing lands the forage availability for animal production is not always predictable. Unstable fodder availability with nutritional deficiencies can cause poor livestock production as animals have to rely mostly on poor quality feeds. Tree and shrub leaves can potentially alleviate some problems of feed shortages and nutritional deficiencies especially for range animals during fodder scarcity seasons. However, it would be essential to estimate the nutritive value of these leaves before their use for feeding animals. This study therefore evaluated different drought resistant and salt tolerant shrubs for their nutrient composition and in vitro dry matter (DM) degradability (IVD) alongside grass nuts (grass) as a good quality processed forage. The results of this study may help design future strategies for the use of these shrubs in ruminant diets to partly overcome the animal feed shortage in some tropical regions.

Materials and methods This $5 \times 7$ factorial study in triplicate compared the IVD of 5 plants including grass nuts as a control and 4 shrubs (Baker or Adhatoda vasica $=A V$; Sanatha or Dodonea viscose $=D V$; Australian acacia or Acacia ampliceps $=A A$; and saltbush or Atriplex lentiformis $=A L)$ at 7 incubation hours $(0,6,12,24,48,72,96)$. A sample of grass nuts that has already been tested in this laboratory was used as a standard control whereas the shrub leaves were collected, dried and transported to the UK. These samples were re-dried and ground through $1 \mathrm{~mm}$ sieve before determining in triplicate their nutrient and total phenolic (TP) contents. Rumen fluid was obtained from 2 fistulated sheep prior to their morning feeding, strained through a cheese cloth into pre-warmed flasks under $\mathrm{CO}_{2}$ and mixed with a pre-warmed buffer at 1:4 ratio to prepare the inoculum which was kept at $39^{\circ} \mathrm{C}$ until used. About $0.4 \mathrm{~g}$ of each sample was weighed into a marked test tube to which $40 \mathrm{ml}$ of the inoculum were added under $\mathrm{CO}_{2}$. The tubes were sealed with rubber stoppers and incubated at $39^{\circ} \mathrm{C}$ for the pre-determined times before placing these tubes in ice to stop fermentation. The residues were collected after centrifuging the tubes at 10,000 rpm for 10 minutes, washed with distilled water and dried at $60^{\circ} \mathrm{C}$ to determine IVD. The data were analyzed by using General Linear Model of SAS $\AA$ to compare the differences between these plants for their nutrients and IVD for each incubation time at $\mathrm{P}<0.05$. The effect of time or the plant $\mathrm{x}$ time interaction was not tested in this analysis. However, the Tukey's posthoc test was used to compare the treatment means for each time at $\mathrm{P}<0.05$.

Results Table 1 shows significant differences between these plants for most nutrients and IVD at each incubation time $(\mathrm{P}<0.05)$. A vasica contained significantly more $\mathrm{CP}$ but less NDF and ADL than other plants including grass nuts $((\mathrm{P}<0.05)$. The patterns of change in IVD of shrubs with increasing times were comparable to that of grass nuts as a control. IVD increased significantly $(\mathrm{P}<0.001)$ with the increased incubation time $(\mathrm{P}<0.001)$. However, the extent of difference between mean IVD of shrubs depended upon the shrub type and the incubation time $(\mathrm{P}<0.001)$. In fact, IVD of $\mathrm{AV}$ and $\mathrm{AL}$ were closer to grass nuts but greater than those of $\mathrm{DV}$ and AA at most incubations times. $D$ viscose contained highest TP but lowest CP and IVD than other shrubs $(\mathrm{P}<0.001)$.

Table 1 Mean nutrient composition and IVD for different incubation hours of tropical shrubs and grass nuts

\begin{tabular}{|c|c|c|c|c|c|c|c|c|c|c|c|c|c|c|}
\hline \multirow[b]{2}{*}{ Items } & \multicolumn{7}{|c|}{ Nutrient composition (g/kg or $\mathrm{g} / \mathrm{kg} \mathrm{DM})$} & \multicolumn{7}{|c|}{ In vitro degradability at hours $(\mathrm{g} / \mathrm{kg})$} \\
\hline & $\mathrm{DM}$ & $\mathrm{OM}$ & $\mathrm{CP}$ & $\mathrm{EE}$ & NDF & ADL & $\mathrm{TP}$ & 0 & 6 & 12 & 24 & 48 & 72 & 96 \\
\hline A vasica & 918 & 840 & 285 & 13 & 231 & 109 & 22 & 258 & 306 & 350 & 393 & 482 & 512 & 539 \\
\hline$D$ viscosa & 922 & 942 & 83 & 17 & 311 & 119 & 73 & 210 & 239 & 259 & 287 & 312 & 339 & 348 \\
\hline A ampliceps & 937 & 874 & 155 & 14 & 574 & 320 & 10 & 199 & 228 & 250 & 289 & 326 & 349 & 391 \\
\hline A lentiformis & 955 & 780 & 106 & 9 & 445 & 134 & 7 & 229 & 263 & 291 & 301 & 398 & 450 & 534 \\
\hline Grass nuts & 940 & 921 & 168 & 29 & 606 & ND & ND & 190 & 240 & 287 & 306 & 414 & 473 & 535 \\
\hline SEM & 1.6 & 13.6 & 8 & 5.6 & 3.9 & 13.1 & 8 & 7 & 8 & 10 & 12 & 18 & 20 & 24 \\
\hline Significance & $*$ & $* * *$ & $* * *$ & NS & $* * *$ & $* * *$ & $* *$ & $* * *$ & $* * *$ & $* * *$ & $* * *$ & $* * *$ & $* * *$ & $* * *$ \\
\hline
\end{tabular}

$\mathrm{ND}=$ not determined; $\mathrm{NS}=$ non significant; $* * *$ and $* * *$ represent significance at $\mathrm{P}<0.05, \mathrm{P}<0.01$ and $\mathrm{P}<0.001$ respectively

Conclusions Although these shrubs showed variable nutrients and IVD in comparison with the grass nuts, they appeared to have the potential for their use in formulating ruminant diets during the feed shortage seasons of different regions of Pakistan. Further studies will look at the suitability of different amounts of these shrubs as potential supplements for forage consuming livestock particularly in tropical countries where animal production is restricted by the feed shortages.

Acknowledgments Thanks to Pakistan Higher Education Commission for funding and Mehedi Khan, Helio Lima Neto and M Safdar Anjum for their help during the laboratory analysis 